\title{
Economic costs analysis of uncomplicated malaria case management in the Peruvian Amazon
}

Diamantina Moreno-Gutierrez ${ }^{1,2,3^{*}{ }^{\prime}}$, Angel Rosas-Aguirre ${ }^{2,4,5+}$, Alejandro Llanos-Cuentas ${ }^{5,6}$, Joke Bilcke ${ }^{3}$, José Luis Barboza ${ }^{5}$, Marie-Pierre Hayette ${ }^{7}$, Juan Contreras-Mancilla, ${ }^{5,8}$, Kristhian Aguirre ${ }^{5}$, Dionicia Gamboa, ${ }^{5,8,9}$, Hugo Rodriguez ${ }^{1}$, Niko Speybroeck ${ }^{2}$ and Philippe Beutels ${ }^{3}$

\begin{abstract}
Background: Case management is one of the principal strategies for malaria control. This study aimed to estimate the economic costs of uncomplicated malaria case management and explore the influence of health-seeking behaviours on those costs.

Methods: A knowledge, attitudes and practices (KAP) survey was applied to 680 households of fifteen communities in Mazan-Loreto in March 2017, then a socio-economic survey was conducted in September 2017 among 161 individuals with confirmed uncomplicated malaria in the past 3 months. Total costs per episode were estimated from both provider (Ministry of Health, $\mathrm{MoH}$ ) and patient perspectives. Direct costs were estimated using a standard costing estimation procedure, while the indirect costs considered the loss of incomes among patients, substitute labourers and companions due to illness in terms of the monthly minimum wage. Sensitivity analysis evaluated the uncertainty of the average cost per episode.

Results: The KAP survey showed that most individuals (79.3\%) that had malaria went to a health facility for a diagnosis and treatment, $2.7 \%$ received those services from community health workers, and $8 \%$ went to a drugstore or were self-treated at home. The average total cost per episode in the Mazan district was US\$161. The cost from the provider's perspective was US\$30.85 per episode while from the patient's perspective the estimated cost was US\$ 131 per episode. The average costs per Plasmodium falciparum episode (US\$180) were higher than those per Plasmodium Vivax episode (US\$ 156) due to longer time lost from work by patients with P. falciparum infections (22.2 days) than by patients with P. vivax infections (17.0 days). The delayed malaria diagnosis (after $48 \mathrm{~h}$ of the onset of symptoms) was associated with the time lost from work due to illness (adjusted mean ratio $1.8 ; 95 \% \mathrm{Cl} 1.3,2.6$ ). The average cost per malaria episode was most sensitive to the uncertainty around the lost productivity cost due to malaria.

Conclusions: Despite the provision of free malaria case management by $\mathrm{MoH}$, there is delay in seeking care and the costs of uncomplicated malaria are mainly borne by the families. These costs are not well perceived by the society and the substantial financial impact of the disease can be frequently undervalued in public policy planning.
\end{abstract}

Keywords: Economic, Cost, Malaria, Management, Health care-seeking behaviour, Peru

\section{*Correspondence: dlmorenog@gmail.com}

${ }^{\dagger}$ Diamantina Moreno-Gutierrez and Angel Rosas-Aguirre contributed equally to this work

${ }^{1}$ Facultad de Medicina Humana, Universidad Nacional de la Amazonía Peruana, lquitos, Loreto 160, Peru

Full list of author information is available at the end of the article

\section{Background}

The good economic performance together with targeted social spending and enhanced anti-poverty programs led Peru to have significant success in improving health outcomes during the Countdown to the 2015 Millennium

(c) The Author(s) 2020. This article is licensed under a Creative Commons Attribution 4.0 International License, which permits use, sharing, adaptation, distribution and reproduction in any medium or format, as long as you give appropriate credit to the original author(s) and the source, provide a link to the Creative Commons licence, and indicate if changes were made. The images or other third party material in this article are included in the article's Creative Commons licence, unless indicated otherwise in a credit line to the material. If material is not included in the article's Creative Commons licence and your intended use is not permitted by statutory regulation or exceeds the permitted use, you will need to obtain permission directly from the copyright holder. To view a copy of this licence, visit http://creativeco mmons.org/licenses/by/4.0/. The Creative Commons Public Domain Dedication waiver (http://creativecommons.org/publicdomain/ zero/1.0/) applies to the data made available in this article, unless otherwise stated in a credit line to the data. 
Development Goals (MDGs) [1]. Currently, the 2030 Sustainable Development Goals (SDGs) "to ensure healthy lives and promote wellbeing for all at all ages" [2] challenge the health sector, not least because Peruvian health expenditure are among the lowest in the Americas (about 5\% of Gross Domestic Product-GDP) [3], substantial health inequities persist [4], and communicable diseases such as malaria resurge $[5,6]$.

Malaria remains an important public health problem in the country despite several decades of intense control efforts [7]. Peru had the third highest increase in malaria incidence (after Venezuela and Nicaragua) since 2010 in the Americas, [8], having reported about 72\% more malaria cases in 2017 (54,309 cases) compared with 2010 (31,545 cases) [9]. The Amazon Region, mainly the department of Loreto, is commonly affected by malaria due to both Plasmodium vivax and Plasmodium falciparum (P. vivax/P. falciparum ratio: 4/1), accounting for more than 95\% of Peru's malaria cases in 2017 (52,280 cases) [9]. The complex association between poverty and malaria is well known, which likely operates in both directions in the poorest districts of Loreto: poor households are more exposed to infectious mosquitoes due to occupational hazards (i.e. subsistence farming and hunting) and less able to afford prevention, and the higher burden of malaria may push these same households deeper into poverty (due to high productivity losses following multiple episodes throughout a year) [10, 11]. Indeed, a former economic evaluation conducted in 1998 from the perspective of society found that malaria costs were mainly borne by the families [11].

In the last two decades, the Peruvian Ministry of Health $(\mathrm{MoH})$ has implemented strategies to improve the population's access to healthcare, especially for people not covered by the contributory social health insurance system (EsSalud), the Armed Forces (FFAA), National Police (PNP), or the private sector [12]. Thus, the Integrated Health Insurance scheme (IHIS), launched in 2009 by $\mathrm{MoH}$, allowed for the expansion of former benefit packages beyond maternal and child health, and the increase of healthcare coverage to the poor and vulnerable populations of all ages [13-15]. Currently, the IHIS and EsSALUD cover about $65 \%$ and $17 \%$ of the total population in Loreto, respectively [16]; however, in poor Amazonian districts that consist mostly of rural communities, the IHIS is often the only possibility to provide health services to the population. The IHIS has reinforced the main pillar interventions for malaria control in Loreto, such as malaria surveillance and case identification through passive case detection (PCD, i.e. malaria detection at health facility or by community health workers $(\mathrm{CHW})$ using standard diagnosis among symptomatic individuals seeking healthcare) or active case detection
(ACD, i.e. malaria detection in the community through household visits) [17, 18], and the effective, free, and timely management of confirmed malaria infections. In the past, those interventions were mainly supported by funding specifically assigned to the National Malaria Control Program (NMCP) at $\mathrm{MoH}$ [11].

From an economic perspective, it was described that the healthcare-seeking behaviours among individuals with malaria-like symptoms can significantly affect the direct and indirect costs associated with malaria detection and management [19]. In areas like Loreto, early and appropriate healthcare-seeking behaviours can save direct costs by halting transmission from confirmed malaria infections, and by avoiding additional costs associated with complications of such infections $[11,20]$. Conversely, delayed behaviours, self-medication, and seeking healthcare from traditional healers can increase the latter direct medical costs, impacting household budgets due to the lost wages and transportation costs during the care-seeking process and the illness period [20]. This study aimed to estimate the economic costs associated with the PCD and management of uncomplicated malaria episodes in riverine communities in the Peruvian Amazon from both the provider's and patient's perspectives, and explore whether healthcare-seeking behaviours significantly influence those costs.

\section{Methods}

\section{Study design and study area}

An epidemiological and knowledge, attitude and practice (KAP) survey, followed by a socio-economic survey were conducted in Mazan district, in the northeastern Peruvian Amazon Department of Loreto. Mazan, with a population of about 13,900 inhabitants living in 70 riverine communities, is considered one of the districts with the highest risk for malaria transmission in Peru [9]. In 2017, its annual parasite index (API) reached 96.4 cases per 1000 inhabitants. Malaria is predominantly caused by $P$. vivax (74\%), and less by P. falciparum (26\%), while its main vector is Anopheles (Nyssorhynchus) darlingi in Peru [21]. The capital and largest village in Mazan, i.e. Mazan town (MT), is located at the confluence of the Mazan and Napo Rivers (3.503 S, 73.094 W), at about $55-60 \mathrm{~km}$ ( 1 hour by speedboat) from Iquitos city (capital of Loreto).

Malaria diagnosis and treatment in healthcare-seeking individuals with malaria-like symptoms are provided free of charge by the $\mathrm{MoH}$ in all Peruvian malaria endemic areas. In Mazan, a health centre in MT and health posts located in six riverine communities are responsible for these activities [22]. With a laboratory service available 6 days a week and two microscopists with accredited competency in species identification according to World 
Health Organization (WHO) standards [23], the health centre in MT is the only health facility in Mazan that provides microscopic diagnosis of malaria and immediate anti-malarial treatment to microscopically-confirmed infected individuals. Unless rapid diagnostic tests (RDTs) are available, health posts need to collect blood smear samples from symptomatic individuals, send them to the health centre, and wait for the parasitological confirmation to initiate anti-malarial treatment. In communities with lack of health facilities, these activities are performed by CHWs, who are regularly trained and supervised by the health facilities. The available RDT during the study period was the SD Bioline Malaria Ag Pf/Pf/ Pv (Standard Diagnostics, South Korea), which detects three malaria antigens in human whole blood: the histidine-rich protein II (HRP-II) antigen of P. falciparum, the Plasmodium lactate dehydrogenase (pLDH) of $P$. falciparum and the pLDH of $P$. vivax [24].

According to national guidelines, $P$. vivax malaria episodes without criteria of severity and hospital admission (i.e. uncomplicated malaria) are treated immediately with chloroquine (CQ) for 3 days (10 mg/kg on days 1 and 2, and $5 \mathrm{mg} / \mathrm{kg}$ on day 3$)$ plus primaquine (PQ) $(0.5 \mathrm{mg} / \mathrm{kg} /$ day) for 7 days; while the first-line treatment for uncomplicated $P$. falciparum malaria consists of artesunate
(AS) for 3 days (4 $\mathrm{mg} / \mathrm{kg} /$ day), mefloquine (MQ) for 2 days $(12.5 \mathrm{mg} / \mathrm{kg} /$ day $)$ and PQ $(0.75 \mathrm{mg} / \mathrm{kg})$ in single dose. Uncomplicated $P$. falciparum-P. vivax coinfections receive AS and MQ at the same doses than those for uncomplicated $P$. falciparum infections, but together with an extended period of PQ $(0.5 \mathrm{mg} / \mathrm{kg} /$ day $)$ for 7 days [25]. In vivo clinical studies have found that both CQ and the combination MQ-AS remain efficacious for the treatment of respectively uncomplicated $P$. vivax and $P$. falciparum infections in the Peruvian Amazon [26, 27].

\section{Study population}

The study population were all households from fifteen communities in Mazan district (Fig. 1). These communities were chosen among the total 70 communities in Mazan, because they accounted for $80 \%$ of reported cases in the district in the period 2016-2017. The Table 1 provides information of study communities about the availability of health facilities, distance in minutes to the health centre, and population. Inhabitants live mainly in open or semi-open wooden houses built on stilts. Subsistence farming is the main economic activity, followed by seasonal logging. Mestizos comprised the majority of the study population [28]; Yagua, Maijuna and Kichwa ethnic groups were present in three communities [29].

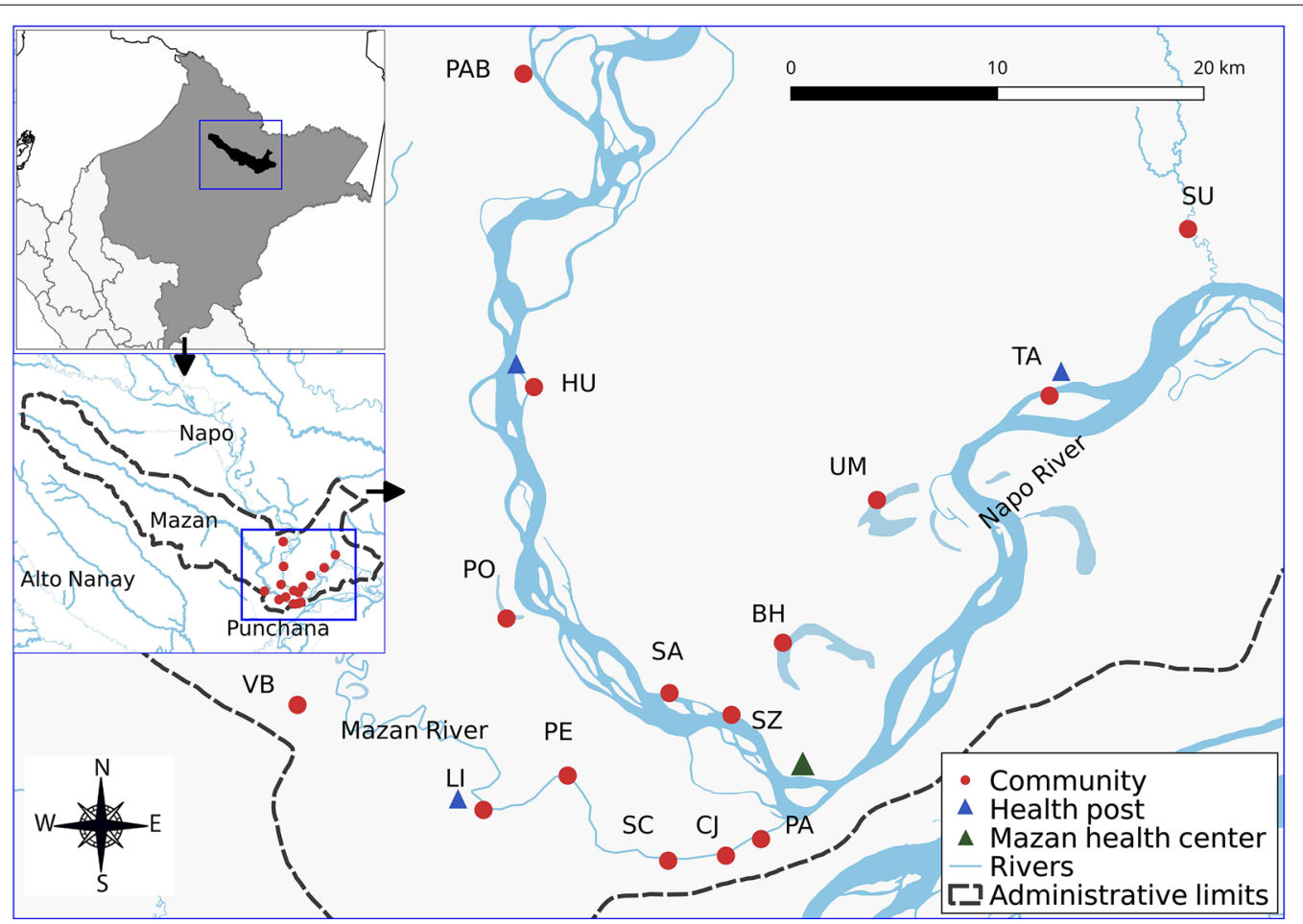

Fig. 1 Study communities in Mazan Loreto, Peru. BH Bello Horizonte, CJ Catorce de Julio, HU Huaman-Urco, LI Libertad, PAB Puerto Abeja, PA Puerto Alegre, PE Primero de Enero, PO Puerto Obrero, SA Salvador, SZ San Antonio de Zambrano, SC Santa Cruz, SU Sucusari, TA Tamanco, UM Urco Miraño, VB Visto Bueno 
Table 1 Health services availability in communities, time to health centre and knowledge, attitudes and practices (KAP) survey

\begin{tabular}{|c|c|c|c|c|c|c|c|}
\hline \multirow[t]{3}{*}{ River basin } & \multirow[t]{3}{*}{ Community } & \multicolumn{2}{|l|}{ Availability } & \multirow{3}{*}{$\begin{array}{l}\text { Time } \\
\text { to the health } \\
\text { centre } \\
\text { Minutes }^{\mathbf{b}}\end{array}$} & \multicolumn{3}{|l|}{ KAP survey } \\
\hline & & \multirow[t]{2}{*}{ Health post ${ }^{a}$} & \multirow{2}{*}{$\begin{array}{l}\text { Community } \\
\text { health worker }\end{array}$} & & \multirow{2}{*}{$\begin{array}{l}\text { Inhabitant } \\
\text { n }\end{array}$} & \multicolumn{2}{|c|}{ Household } \\
\hline & & & & & & $\mathrm{n}$ & $\%$ \\
\hline \multirow[t]{6}{*}{ Mazan } & Primero de Enero & No & Yes & 135 & 133 & 25 & 3.7 \\
\hline & Visto Bueno & No & Yes & 275 & 79 & 15 & 2.2 \\
\hline & 14 de Julio & No & Yes & 30 & 136 & 23 & 3.4 \\
\hline & Santa Cruz & No & Yes & 45 & 439 & 73 & 10.7 \\
\hline & Libertad & Yes & Yes & 155 & 374 & 64 & 9.4 \\
\hline & Puerto Alegre & No & Yes & 15 & 353 & 57 & 8.4 \\
\hline Subtotal Mazan & & & & & 1514 & 257 & 37.8 \\
\hline \multirow[t]{9}{*}{ Napo } & Huaman Urco & Yes & Yes & 195 & 502 & 85 & 12.5 \\
\hline & San Antonio de Zambrano & No & Yes & 30 & 124 & 24 & 3.5 \\
\hline & Urco Mirañoc & No & No & 225 & 371 & 54 & 7.9 \\
\hline & Bello Horizonte & No & Yes & 80 & 285 & 47 & 6.9 \\
\hline & Puerto Abejac & No & Yes & 315 & 109 & 19 & 2.8 \\
\hline & Tamanco & Yes & No & 180 & 228 & 49 & 7.2 \\
\hline & Puerto Obrero & No & No & 105 & 109 & 21 & 3.1 \\
\hline & Salvador & No & Yes & 45 & 456 & 91 & 13.4 \\
\hline & Sucusaric & No & Yes & 270 & 179 & 33 & 4.9 \\
\hline Subtotal Napo & & & & & 2363 & 423 & 62.2 \\
\hline Total & & & & & 3877 & 680 & 100 \\
\hline
\end{tabular}

\section{Data collection}

The study field team, composed of two trained health technicians and two nurses, traveled to selected communities in motorized boats and collected data over a few days. An epidemiological and KAP survey was conducted in all available households in March 2017. Prior informed consent, household members were censused, the house location geo-referenced, and the socio-demographic characteristics were collected (e.g. household size, predominant construction materials in house, ownership of bed nets, and availability of essential services such as water for domestic use, sanitation facility and electricity). A KAP survey questionnaire was applied to the household's head or the designate to gather information on family's attitudes, understanding of malaria transmission, recognition of signs and symptoms, perceptions of cause, care-seeking patterns, preventive measures and practices. Questionnaires were programmed using the Open Data Kit (ODK) application on mobile devices without a network connection.

A second survey (socio-economic survey) was conducted in September 2017 to obtain detailed information about the household's care-seeking process and the cost of illness. The survey questionnaire was applied to a subpopulation of households, of which at least one member had been diagnosed with uncomplicated malaria in the previous 3 months before the survey (June-August 2017). Households were visited up to three times in a period of three days to maximize study participation. When recurrent episodes were recorded for an individual in the past 3 months, only those recorded at intervals of more than 28 days were considered as independent episodes. Besides the registration of socio-demographic data and clinical features of malaria episodes on mobile devices, participants or responsible relatives (in case of minors) were also asked to complete a semi-structured questionnaire on treatment-seeking. The latter contained questions on all the places they visited to seek care/treatment, whether they had blood tests and the type of these tests, the time between the onset of symptoms and the confirmation of malaria infection, and the type of treatment they received. The questionnaire also allowed obtaining specific data for the estimation of direct and indirect household costs associated with malaria episodes. These included costs of transport during the care-seeking process, time lost from work due to illness for patients, their 
carers/companions (i.e. individuals who care informally for the patient at home, and/or accompany him/her during the healthcare-seeking) and substitute labourers (i.e. economically active individuals who substitute malaria patients at work).

\section{Data analysis}

The analysis was performed using STATA 12.1 software (Statacorp, College Station, TX, USA) and R v.2.15 software ( $\mathrm{R}$ Development Core Team, R Foundation for Statistical Computing, Vienna, Austria). Household characteristics from KAP survey, and individual sociodemographic data from the socio-economic survey were described using absolute and relative frequencies.

Univariate and multivariate generalized linear models with gamma distribution were used to test the association between the time lost due to illness and the time to malaria diagnosis (i.e. time from onset of symptoms to malaria confirmation by diagnostic test) in economically active patients ( $\geq 15$ years) [30]. Adjusted mean ratios
(Adj.MR) and the corresponding 95\% confidence intervals $(95 \% \mathrm{CI})$ measured how much more time patients lost due to illness, considering the Plasmodium species that caused the malaria episode, the diagnostic test that confirmed malaria, gender, education level and the time to the health centre in MT as potential confounders. All statistical analysis considered a $\mathrm{p}$ value $<0.05$ as statistically significant.

\section{Cost estimates}

Costs associated with uncomplicated malaria episodes in Mazan were estimated for the year 2017 from both the provider and patient perspectives. These estimates drew on the number of malaria episodes registered by the PCD's surveillance in the district, as well as base case parameters (i.e. cost parameters or unit costs). Table 2 shows that the socio-economic survey provided data of cost parameters for estimating costs from the patient perspective; while costing databases from the $\mathrm{MoH}$ were required to estimate costs from the provider perspective

Table 2 Parameters, base case estimates and uncertainty distributions for sensitivity analysis

\begin{tabular}{|c|c|c|c|c|}
\hline Parameter & Distribution & $\begin{array}{l}\text { Base case (mean, } \\
\text { proportion) }\end{array}$ & $\begin{array}{l}\text { Standard } \\
\text { error (SE) }\end{array}$ & Source \\
\hline Malaria in Mazan in 2017, episodes & - & 1344 & - & EDB \\
\hline Malaria episodes caused by Pf, proportion & - & 0.23 & - & EDB \\
\hline Economically active (EA) Pv patient, probability & Beta & 0.56 & 0.04 & SES \\
\hline Economically active (EA) Pf patient, probability & Beta & 0.69 & 0.06 & SES \\
\hline Economically active (EA) companion of a Pv patient, probability & Beta & 0.83 & 0.03 & SES \\
\hline Economically active (EA) companion of a Pf patient, probability & Beta & 0.73 & 0.06 & SES \\
\hline Confirmed malaria by LM or RDT among symptomatic individuals, proportion & - & 0.16 & - & $\mathrm{EDB}$ \\
\hline Healthcare-seeking with CHW (and not health facilities), proportion & Beta & 0.17 & 0.03 & SES \\
\hline Utilization of RDT (instead of LM) at health facilities for malaria confirmation, proportion & Beta & 0.21 & 0.03 & SES \\
\hline Cost of complete Pv malaria treatment, unit cost, US\$ & Gamma & 1.32 & 0.38 & $\mathrm{CDB}$ \\
\hline Cost of complete Pf malaria treatment, unit cost, US\$ & Gamma & 8.76 & 2.76 & $\mathrm{CDB}$ \\
\hline Cost of consultation, staff-related unit cost, US\$ & Gamma & 1.81 & 0.05 & $\mathrm{CDB}$ \\
\hline Cost of consultation, non staff-related unit cost, US\$ & - & 0.77 & - & $\mathrm{CDB}$ \\
\hline Cost of diagnosis using LM, staff-related unit cost, US\$ & Gamma & 0.50 & 0.01 & $\mathrm{CDB}$ \\
\hline Cost of diagnosis using LM, non staff-related unit cost, US\$ & - & 0.21 & - & $\mathrm{CDB}$ \\
\hline Cost of diagnosis using RDT, staff-related unit cost, US\$ & Gamma & 0.50 & 0.01 & $\mathrm{CDB}$ \\
\hline Cost of diagnosis using RDT, non staff-related unit cost, US\$ & - & 0.40 & - & $\mathrm{CDB}$ \\
\hline Cost of diagnosis using RDT, test-related unit cost, US\$ & Gamma & 1.07 & 0.33 & $\mathrm{CDB}$ \\
\hline Cost of transport Pv patient, unit cost, US\$ & Gamma & 2.36 & 0.35 & SES \\
\hline Cost of transport companion of Pv patient, unit cost, US\$ & Gamma & 1.94 & 0.31 & SES \\
\hline Cost of transport Pf patient, unit cost, US\$ & Gamma & 2.78 & 1.17 & SES \\
\hline Cost of transport companion of Pf patient, unit cost, US\$ & Gamma & 0.64 & 0.23 & SES \\
\hline Time lost due to illness in an EA Pv patient, person-days & Gamma & 10.21 & 0.99 & SES \\
\hline Time lost due to illness in an EA Pf patient, person-days & Gamma & 11.80 & 1.48 & SES \\
\hline Time lost in EA companions of a Pv patient, person-days & Gamma & 7.73 & 0.50 & SES \\
\hline Time lost in EA companions of a Pf patient, person-days & Gamma & 6.85 & 0.90 & SES \\
\hline
\end{tabular}

$\mathrm{PV}$, P. vivax; Pf, P. falciparum; LM, light Microscopy; RDT, rapid diagnostic test; CHW, community health worker; CDB, cost database; EDB epidemiologic database; SES, socio-economic survey 
since malaria detection and case-management is provided free-of-charge at health facilities [31]. Units costs in Peruvian Nuevos Soles (PEN) were converted into United States Dollars (US\$) using the average exchange rate for 2017 (one US\$ = 3.3 PEN) [33].

\section{Provider perspective, direct costs}

Direct costs from the provider perspective are costs related to the malaria detection (i.e. initial consultations), diagnosis confirmation (using LM or RDTs), appropriate treatment (i.e. antipyretic drugs, anti-malarial drugs) and follow-up (consultation and LM after treatment). The unit costs for care services provided by voluntary $\mathrm{CHW}$ were estimated using the standard shadow price approximation based on the 2017 national minimum wage of US\$ 257.6 per month. Moreover, the unit cost's components (i.e. staff costs, drug/supply costs, or other non-staff costs) that most contributed to the unit cost's variability of care services provided by either health facilities or CHW were identified. As expected, the different salary levels between health staff, resulting in different costs of their time dedicated to a given care service, contributed most to the variability of unit costs. A malaria positivity rate of $15.5 \%$ (base case parameter in 2017) among symptomatic individuals seeking for care was assumed to estimate the number of initial consultations that allow for the identification of malaria cases. It was assumed that a symptomatic individual seeking for care had only one initial consultation. The standard treatment of malaria episodes by species [25] was costed considering that patients $\geq 15$ years old had an average of 60 Kilograms (Kg); whereas, in patients $<15$ years old were considered half of the total doses. Similarly, the administration of the antipyretic acetaminophen was costed considering that adults receive 10 tablets $(500 \mathrm{mg})$ and that children take syrup $(120 \mathrm{mg} / 5 \mathrm{ml} /)$ [25, 30]. Follow-up costs considered that $P$. vivax and $P$. falciparum episodes require respectively one and two follow-ups as national guidelines states [25].

\section{Patient perspective, direct costs}

Direct costs from the patient perspective, comprised other medications not provided free-of-charge by the provider, such as analgesics, the transport costs for the patient and companions, and other costs (e.g. consumed food during the care-seeking process). Cost calculations were based on the volume and unit cost data collected through the socio-economic survey (Table 2).

\section{Patient perspective, indirect costs}

Indirect costs from the patient perspective included the lost wages due to malaria per patient, substitute labourers and companions. Lost wages were calculated for only individuals $\geq 15$ years old only (i.e. economically active sub-population) [32, 33], by multiplying the reported time lost from work in days (cost parameter expressed in person-days) by the amount of money lost in 1 day for not working (person-day unit cost). Person-day unit costs (US\$ 9.91) for patients, substitutes and companions were calculated using the monthly minimum wage of 2017 (US\$ 257.6) as reference, by dividing it by the number of working days per month [34].

\section{Total costs and average cost per episode}

The sum of costs from the provider and patient perspectives yielded the average total costs for all malaria episodes during 1 year, and the division between these average total costs by the number of episodes the average cost per episode. Both costs were calculated overall and by species.

\section{Uncertainty and sensitivity analysis}

Multi-way probabilistic sensitivity analysis (PSA) estimated the confidence in the average cost per malaria episode. This considered the uncertainty that surrounded the base case parameters (point estimates) which were used in the calculation of such average cost [35]. Since base case estimates based on few data are more uncertain (less confidence) than estimates based on large datasets, it was accounted by this uncertainty by first defining probability distributions for the relevant cost parameters (Table 2). The rationale for the assumed distribution for each parameter has been described elsewhere [35, 36]. The beta distribution was chosen for the probability of being economically active either among malaria-infected individuals or companions; while the gamma distribution was used for unit costs (i.e. unit costs related to malaria detection, diagnosis and treatment, and costs associated with the transport of patients and their companions) and the time lost from work due to malaria (Table 2). Second, Monte Carlo simulations were conducted in $\mathrm{R}$ software to propagate uncertainty by sampling values from all the probability distributions jointly in 10,000 iterations and calculating the corresponding values for the cost per malaria episode. Third, upper and lower $95 \%$ uncertainty limits (2.5 and 97.5\%) for the average cost per malaria episode were obtained from these simulations and reported using tornado diagrams.

A one-way PSA was also used to assess how sensitive the average cost per species-specific episode was to changes in individual uncertain parameters by sampling from the uncertainty distribution of a single parameter, while fixing the other uncertain parameter to their base case value. The gross domestic product (GDP) of Peru in 2017 [37] was also tested as reference in the sensitivity analysis to estimate person-day unit costs (US\$ 21.1) 
for patients, substitutes and companions, and to adjust the staff-costs associated with the health care services. The latter adjustment consisted in a multiplication by 2.1 (division of person-day unit cost using the GDP reference by that using the monthly minimum wage reference).

\section{Results}

\section{Household characteristics}

A total 680 households and 3877 residents were censused (Table 1). Household with more than three people per habitable room (overcrowding) (57.2\%) and housing structures with incomplete walls (60.5\%) were frequent in the study area. Most individuals lived in houses with wooden walls and roofs composed of palm leaf. Most households had no sanitation facility and lack of electricity. Main sources of water for domestic use were the river and the rain (Table 3).

\section{Malaria knowledge, attitudes and practices (KAP) Knowledge}

Although most of the 680 responders knew that malaria is transmitted by infected mosquitoes; $22 \%$ of responders pointed out that malaria was acquired by drinking stagnant water and nobody knew that malaria could be transmitted through blood transfusion. Fever, headache and chills were identified as the most common symptoms (about $80 \%$ of responders) in individuals with malaria disease; myalgia/arthralgia, nausea/vomiting and general discomfort were also recognized as malaria symptoms (>15\% of responders). The majority $(>90 \%)$ of responders knew that malaria can be acquired more than once and that medication can cure the disease. Health workers followed by $\mathrm{CHW}$ were referred as the main sources of information about malaria (Additional file 1: Table S1).

\section{Attitudes}

The majority of responders (80.6\%) would go to a health facility as first action in case of malaria symptoms, despite the perception (53.5\% of responders) that getting malaria was common and normal (Additional file 1: Table S2). The $\mathrm{MoH}$ was identified as the main responsible for malaria control (about $60 \%$ of respondents), followed by CHW. Almost all responders (>98\%) referred that a finger-prick blood smear was necessary to determine if a person had malaria. Regarding the anti-malarial treatment, about half the responders were aware that interrupting the treatment could lead to a severe illness/death, or to malaria recurrences. The majority of responders perceived that the presence of standing water increased the risk of malaria (88.7\%), that the presence of mosquitoes was a nuisance to them (94.3\%), and that the use of bed net was not annoying (90.9\%).
Table 3 Baseline household characteristics of the study area

\begin{tabular}{|c|c|c|}
\hline Characteristics & $N=680$ & $\%$ \\
\hline \multicolumn{3}{|c|}{ Housing structure (number of external walls) } \\
\hline 0 & 99 & 14.6 \\
\hline $1-3$ & 312 & 45.9 \\
\hline 4 & 269 & 39.6 \\
\hline \multicolumn{3}{|l|}{ Main material in walls $(n=581)^{\text {a }}$} \\
\hline Wood & 551 & 94.8 \\
\hline Brick & 2 & 0.3 \\
\hline Others (adobe, straw, palm) & 28 & 4.8 \\
\hline \multicolumn{3}{|l|}{ Main material in floor } \\
\hline Wood & 659 & 96.9 \\
\hline Cement or other fine finish & 12 & 1.8 \\
\hline Soil & 9 & 1.3 \\
\hline \multicolumn{3}{|l|}{ Main material in roof } \\
\hline Palm leaf, straw & 446 & 65.7 \\
\hline Tin & 233 & 34.3 \\
\hline Missing & 1 & \\
\hline \multicolumn{3}{|l|}{ Overcrowding } \\
\hline No & 291 & 42.8 \\
\hline Yes & 389 & 57.2 \\
\hline \multicolumn{3}{|l|}{ Sanitation facility } \\
\hline No facility, field & 528 & 77.9 \\
\hline Pit latrine, ground dug & 150 & 22.1 \\
\hline Missing & 2 & \\
\hline \multicolumn{3}{|c|}{ Source of water for domestic use } \\
\hline River, rain & 601 & 88.4 \\
\hline Open well, public tap & 79 & 11.6 \\
\hline \multicolumn{3}{|l|}{ Electricity available } \\
\hline No & 473 & 69.7 \\
\hline Yes & 206 & 30.3 \\
\hline Missing & 1 & \\
\hline \multicolumn{3}{|l|}{ Radio available } \\
\hline No & 302 & 44.4 \\
\hline Yes & 378 & 55.6 \\
\hline \multicolumn{3}{|l|}{ Ownership of bed nets } \\
\hline \multicolumn{3}{|c|}{ At least one insecticide treated net (ITN) for every two people } \\
\hline No & 453 & 66.6 \\
\hline Yes & 227 & 33.4 \\
\hline \multicolumn{3}{|c|}{ At least one untreated net for every two people } \\
\hline No & 358 & 52.7 \\
\hline Yes & 322 & 47.4 \\
\hline \multicolumn{3}{|c|}{ At least one ITN/untreated net for every two people } \\
\hline No & 109 & 16.0 \\
\hline Yes & 571 & 84.0 \\
\hline \multicolumn{3}{|c|}{ Indoor residual spraying (previous 12 months) } \\
\hline No & 310 & 46.1 \\
\hline Yes & 363 & 53.9 \\
\hline Missing & 7 & \\
\hline
\end{tabular}

${ }^{a}$ Only in household with external walls 


\section{Practices}

When they or their relatives had malaria, the majority of responders $(79.3 \%, 525 / 662)$ indicated they consulted with health services or with CHW $(12.7 \%, 84 / 662)$ (Additional file 1: Table S3). Regarding indoor malaria prevention measures, the most common practices was cleaning the house $(51.4 \%)$ followed by using bed nets (23.0\%), drinking boiled/chlorinated water $(22.7 \%)$ and covering water containers (19.0\%). A majority (58.6\%) also responded that cleaning of house surroundings was the main outdoor malaria prevention measure, followed by clearing objects that can accumulate water (23.2\%) and vegetation $(21.4 \%)$.

\section{Socio-economic survey}

In September 2017, 161 individuals (in 112 households) were enrolled in the socio-economic survey of 251 individuals registered by health services as having had malaria between June-August 2017. Non-enrolled individuals were recent migrants or were not available at household during the survey. Of the total 161 enrolled individuals, 147 (91.3\%) individuals presented only one uncomplicated malaria episode, and 14 (8.7\%) individuals two malaria episodes. Among the total 175 registered episodes, 124 (70.9\%) were by $P$. vivax, $47(26.9 \%)$ by $P$. falciparum, and four (2.3\%) co-infections by both parasite species (Additional file 1: Table S4).

Overall, males outnumbered females (ratio male/ female $=1.15$ ), and economically active individuals ( $\geq 15$ years) representing about half of total patients reported subsistence farming (81.5\%) as the most commonly reported occupation (Table 4). Monthly income in the latter age group ranged from US\$ 0 to US\$ 121. Moreover, the highest educational attainment of the majority of individuals $\geq 18$ years was primary school level (60.3\%) with no statistical differences between basins. More than 95\% of enrolled individuals had health insurance (i.e. IHIS) and reported having used a bed net the previous night. Canoeing (by dugout canoe "pekepeke") (47.2\%) and walking (47.2\%) were the main modes of transportation to reach the point of diagnosis and treatment.

Table 5 shows the place to which individuals with malaria sought care for the first time. CHWs (71, 40.6\%) were the most consulted, followed by health posts $(59$, $33.7 \%)$, the health centre $(43,24.6 \%)$, a hospital $(1,0.6 \%)$ and a pharmacy $(1,0.6 \%)$. When the first consultation was with CHWs, $40.8 \%$ (29/71) of the patients had immediate diagnosis with RDT and treatment, however two patients visited the health centre later (because treatment was not available). The remaining 59.2\% (42/71) of the patients had a blood smear taken which was sent to
Table 4 Socio-demographic characteristics of malaria patient

\begin{tabular}{|c|c|c|}
\hline Characteristics & $N=161$ & $\%$ \\
\hline \multicolumn{3}{|l|}{ Gender } \\
\hline Female & 75 & 46.6 \\
\hline Male & 86 & 53.4 \\
\hline \multicolumn{3}{|l|}{ Age (years) } \\
\hline $1-4$ & 24 & 14.9 \\
\hline $5-14$ & 56 & 34.8 \\
\hline$\geq 15$ & 81 & 50.3 \\
\hline \multicolumn{3}{|l|}{ Education ( $\geq 18$ years) $n=68$} \\
\hline None & 8 & 11.8 \\
\hline Primary school & 41 & 60.3 \\
\hline Secondary school & 19 & 27.9 \\
\hline \multicolumn{3}{|l|}{ Main occupation ( $\geq 15$ years) $n=81$} \\
\hline Logger & 2 & 2.5 \\
\hline Farmer & 66 & 81.5 \\
\hline Housewife & 3 & 3.7 \\
\hline Student & 6 & 7.4 \\
\hline Merchant & 3 & 3.7 \\
\hline Distiller & 1 & 1.2 \\
\hline \multicolumn{3}{|l|}{ Malaria species } \\
\hline P. vivax & 113 & 70.2 \\
\hline P. falciparum & 44 & 27.3 \\
\hline Co-infection (P. vivax-P. falciparum) & 4 & 2.5 \\
\hline \multicolumn{3}{|l|}{ Monthly income amount ( $\geq 15$ years) } \\
\hline None & 10 & 12.4 \\
\hline US\$ 3-121 & 71 & 87.6 \\
\hline \multicolumn{3}{|c|}{ Type of transportation to the point of diagnosis/treatment } \\
\hline None (live in the same place) & 2 & 1.2 \\
\hline Foot & 76 & 47.2 \\
\hline Mototaxi/Motorcycle & 2 & 1.2 \\
\hline Dugout canoe & 76 & 47.2 \\
\hline Row-boat & 1 & 0.6 \\
\hline Foot+Mototaxi/Motorcycle & 1 & 0.6 \\
\hline Foot + dugout canoe & 2 & 0.6 \\
\hline Van & 1 & 1.2 \\
\hline
\end{tabular}

the health centre through an informal fluvial courier for a malaria microscopic diagnosis. With the exception of a single patient who went to the health centre to receive his/her diagnosis and treatment, everyone else came back two-six hours later or the following day for the malaria diagnosis and treatment. Malaria result was communicated by radio to the $\mathrm{CHW}$ when radio was available in the community, or sent back through the informal fluvial courier. When the first consultation was at health post, $49.2 \%(29 / 59)$ of the patients had immediate diagnosis with RDT and treatment, and 30 (50.8\%) had a blood smear sent to the health centre for malaria microscopic 
Table 5 Characteristics of malaria episodes by diagnosis test

\begin{tabular}{|c|c|c|c|c|c|c|c|c|c|c|}
\hline \multirow[t]{3}{*}{ Variable } & \multicolumn{2}{|l|}{ LM } & \multicolumn{2}{|c|}{ RDT } & \multicolumn{2}{|c|}{ Total } & \multicolumn{2}{|c|}{ Time to diagnosis (days) } & \multicolumn{2}{|c|}{ Time lost (days) } \\
\hline & \multirow[b]{2}{*}{$\mathbf{n}$} & \multirow[b]{2}{*}{$\%$} & \multirow[b]{2}{*}{$\mathrm{n}$} & \multirow[b]{2}{*}{$\%$} & \multirow[b]{2}{*}{$\mathrm{n}$} & \multirow[b]{2}{*}{$\%$} & \multirow{2}{*}{$\begin{array}{l}\text { LM } \\
\text { median(IQR) }\end{array}$} & \multirow{2}{*}{$\begin{array}{l}\text { RDT } \\
\text { median(IQR) }\end{array}$} & \multirow{2}{*}{$\begin{array}{l}\mathrm{LM} \\
\text { median(IQR) }\end{array}$} & \multirow{2}{*}{$\begin{array}{l}\text { RDT } \\
\text { median(IQR) }\end{array}$} \\
\hline & & & & & & & & & & \\
\hline \multicolumn{11}{|l|}{ Consultation $(\mathrm{N}=175)$} \\
\hline Health post & 30 & 50.9 & 29 & 49.2 & 59 & 100 & & & & \\
\hline Health centre & 42 & 97.7 & 1 & 2.3 & 43 & 100 & & & & \\
\hline Hospital & 1 & 100.0 & 0 & 0.0 & 1 & 100 & & & & \\
\hline $\mathrm{CHW}$ & 41 & 60.3 & 27 & 39.7 & 68 & 100 & & & & \\
\hline Pharmacy then health centre & 1 & 100.0 & 0 & 0.0 & 1 & 100 & & & & \\
\hline $\mathrm{CHW}$ then health centre & 1 & 33.3 & 2 & 66.7 & 3 & 100 & & & & \\
\hline \multicolumn{11}{|l|}{ Malaria species $(\mathrm{N}=175)$} \\
\hline P. vivax & 76 & 61.3 & 48 & 38.7 & 124 & 100 & $3(2-7)$ & $3(2-3)$ & & \\
\hline P. falciparum & 40 & 78.4 & 11 & 21.6 & 51 & 100 & $3(2-7)$ & $2(2-6)$ & & \\
\hline \multicolumn{11}{|c|}{ Malaria species in EA individuals $(\mathrm{N}=85)^{*}$} \\
\hline P. vivax & 38 & 69.1 & 17 & 30.9 & 55 & 100 & $4.5(3-7)$ & $3(2-3)$ & $7.5(5-15)$ & $7(4-13)$ \\
\hline P. falciparum & 24 & 80.0 & 6 & 20.0 & 30 & 100 & $3(2.5-7)$ & $2.5(2-7)$ & $8.5(7-16.5)$ & $8.5(5-14)$ \\
\hline
\end{tabular}

CHW, Community health worker; EA, economically active; LM, light microscopy; RDT, rapid diagnostic test; IQR, interquartile range

${ }^{*} p$ value $<0.05$ for differences in time to diagnosis (LM vs RDT)

diagnosis. The latter patients came back two-six hours later or the following day for the malaria diagnosis and treatment. Malaria result was communicated by radio to the health posts. The initial seeking for the care at the health centre $(43,24.6 \%)$ and at hospital $(1,0.6 \%)$ always involved microscopic diagnosis by LM, except in one case diagnosed by RDT at the health centre. An additional individual sought for initial care at the pharmacy, but the malaria diagnosis was done at health centre.

Only 65 (37.1\%) episodes were confirmed within $48 \mathrm{~h}$ of the onset of symptoms. Time to diagnosis had a median (mdn) of 3 days and interquartile range (IQR) of 2-5 days, with no differences between malaria episodes by $P$. vivax and $P$. falciparum (Table 5). Considering episodes in only economically active individuals, time to malaria diagnosis was significantly shorter when diagnosis was done by RDT than by microscopy $(p=0.01)$. The analysis by species, showed that these differences were especially for $P$. vivax episodes $(p=0.01)$. However, there were not significant differences in the time lost due to malaria between individuals with episodes diagnosed by RDT and those by microscopy ( $p=0.50$ for $P$. vivax, $p=0.62$ for $P$. falciparum). Gamma distribution models found a significant association between the reported time to malaria diagnosis and the time lost due to malaria illness in economically active patients, with near twice the time lost due to illness in patients who had the malaria diagnosis after $48 \mathrm{~h}$ of the onset of symptoms in comparison who those who had the diagnosis before (Adj. MR 1.8; 95\% CI 1.3, 2.6) (Table 6).

\section{Costs for uncomplicated malaria episodes}

The total costs, for patients and providers combined, associated with 1344 uncomplicated malaria episodes in Mazan in 2017 were US\$ 217,006: US\$ 160,285 corresponding to $1029 P$. vivax episodes and US\$ 56,721 to 315 P. falciparum episodes (Table 7). Therefore, average costs amounted to US\$ 161 per average episode or US\$ 156 per $P$. vivax episode and US\$ 180 per $P$. falciparum episodes. The indirect costs (due to time lost from work) incurred by patients contribute to $78 \%$ of the total costs (Table 7).

From the provider perspective, estimated costs in Mazan were US\$ 41,466 (US\$ 30.85 per episode), including US\$ 29,451 associated with $1029 P$. vivax episodes (US\$ 28.62 per episode) and US\$ 12,015 with 315 P. falciparum episodes (US\$ 38.14 per episode). As Additional file 1: Tables S5 and S6 show, costs associated with initial consultations and malaria screenings (by LM or RDT) accounted for most of provider costs for both $P$. vivax (76.40\%) and P. falciparum (57.35\%). Moreover, costs of anti-malarial treatment and follow-up control after treatment for one P. falciparum episode (US\$ 13.13 and US\$ 6.41) were higher than those for one $P$. vivax episode (US\$ 1.98 and US\$ 3.20).

From the patient perspective, estimated costs for uncomplicated malaria episodes in Mazan were US\$ 175,540 (US\$ 131 per episode), including US\$ 5848 (US\$ 4.35 per episode) as direct costs and US\$ 169,693 (US\$ 126 per episode) as indirect costs. The analysis by species showed that the average costs per $P$. falciparum episode (US\$ 142) were higher than those per $P$. vivax episode 
Table 6 Generalized linear models of time lost due to malaria in economically active patients ( $\geq 15$ years old)

\begin{tabular}{|c|c|c|c|c|c|c|}
\hline \multirow[t]{2}{*}{ Variable } & \multicolumn{4}{|c|}{ Univariate } & \multicolumn{2}{|l|}{ Multivariate } \\
\hline & $\mathbf{N}$ & PD mean (SD) & Mean ratio & {$[95 \% \mathrm{Cl}]$} & Mean ratio & {$[95 \% \mathrm{Cl}]$} \\
\hline \multicolumn{7}{|l|}{ Delayed diagnosis } \\
\hline No (0-48 h) & 26 & $7.2(7.4)$ & Ref & & Ref & \\
\hline Yes (> 48 h) & 59 & $12.3(8.5)$ & 1.7 & {$[1.2 ; 2.4]$} & 1.8 & {$[1.3 ; 2.6]$} \\
\hline \multicolumn{7}{|l|}{ Diagnosis test } \\
\hline RDT & 23 & $9.4(7.4)$ & Ref & & Ref & \\
\hline Microscopy & 62 & $11.3(8.7)$ & 1.2 & {$[0.8 ; 1.7]$} & 1.2 & {$[0.8 ; 1.7]$} \\
\hline \multicolumn{7}{|l|}{ Malaria species } \\
\hline P. vivax & 55 & $10.2(8.3)$ & Ref & & Ref & \\
\hline P. falciparum & 30 & $11.8(8.7)$ & 1.2 & {$[0.8 ; 1.7]$} & 1.2 & {$[0.8 ; 1.6]$} \\
\hline \multicolumn{7}{|l|}{ Gender } \\
\hline Female & 39 & $11.5(9.1)$ & Ref & & Ref & \\
\hline Male & 46 & $10.1(7.8)$ & 0.9 & {$[0.6 ; 1.2]$} & 0.9 & {$[0.6 ; 1.3]$} \\
\hline \multicolumn{7}{|l|}{ Education level } \\
\hline Primary or higher & 76 & $10.3(8.0)$ & Ref & & Ref & \\
\hline No education & 9 & $14.3(11.3)$ & 1.4 & {$[0.8 ; 2.5]$} & 1.6 & {$[1.0 ; 2.8]$} \\
\hline \multicolumn{7}{|c|}{ Time to the health centre } \\
\hline$<120 \min$ & 46 & $9.5(7.1)$ & Ref & & Ref & \\
\hline$\geq 120 \min$ & 39 & $12.3(9.7)$ & 1.3 & {$[0.9 ; 1.8]$} & 1.2 & {$[0.8 ; 1.7]$} \\
\hline
\end{tabular}

$\mathrm{PD}$, person-day; $95 \% \mathrm{Cl}$, 95\% confidence interval; SD, standard deviation

(US\$ 127) (Table 7). The longer time lost by patients due to $P$. falciparum episodes (22.20 days) in comparison with $P$. vivax episodes (17.0 days) determined the higher indirect costs for $P$. falciparum episodes (US\$ 138 per episode) in comparison with those for $P$. vivax episodes (US\$ 123 per episode) (Additional file 1: Tables S7 and S8).

\section{Uncertainty and sensitivity analysis}

Multi-way PSA, accounting for the uncertainty of all relevant cost parameters at the same time and considering the monthly minimum wage as reference, found confidence intervals $(95 \% \mathrm{CI})$ for the average cost per episode between US\$ 139 and US\$ 174 for P. vivax, and between US\$ 152 and US\$ 211 for P. falciparum (gray bars in Fig. 2a, c).

According to the one-way PSA, the uncertainty about the four parameters related to the cost of loss of productivity due to malaria, induced most of the uncertainty in the average cost per malaria episode (second, third, fourth and fifth coloured bars in Fig. 2a, c). Of these four, the uncertainty about the time lost due to malaria in an economically active patient had most impact on the average cost per episode, with estimates between US\$ 146 and US\$ 167 per $P$. vivax episode, and between US\$ 162 and US\$ 200 per $P$. falciparum episode. The uncertainty about the proportion of patients $\geq 15$ years (economically active individuals) was less influential, with estimates of average cost per episode between US\$ 147 and US\$ 165 per P. vivax episode, and between US\$ 164 and US\$ 195 per P. falciparum episode. Similarly, the uncertainty about having economically active companions resulted in average costs between US\$ 150 and US\$ 160 per $P$. vivax episode, and between US\$ 172 and US\$ 188 per $P$. falciparum episode. But, again the uncertainty in the time lost in economically active companions during the healthcare-seeking, malaria diagnosis and treatment of a malaria patient caused more uncertainty in the average cost estimates: between US\$ 148 and US\$ 164 per P. vivax episode and between US\$ 168 and US\$ 193 per $P$. falciparum episode. Uncertainties about the cost of anti-malarial drugs, the cost of malaria detection and diagnosis, and the cost of transport resulted in the smallest uncertainty intervals of the average costs per episode.

When GDP was used as reference to estimate personday unit costs, the base case average costs increased to US\$ 314 per P. vivax episode, and to US\$ 358 per P. falciparum episode (Table 7). Multi-way PSA found averages cost ranges between US\$ 278 and US\$ 352 per P. vivax episode, and between US\$ 299 and US\$ 423 per P. falciparum episode (gray bars in Fig. 2b, d). The most influential parameters for the average cost per malaria episode were also those that determined the cost of loss of productivity due to malaria according to the one-way PSA. 


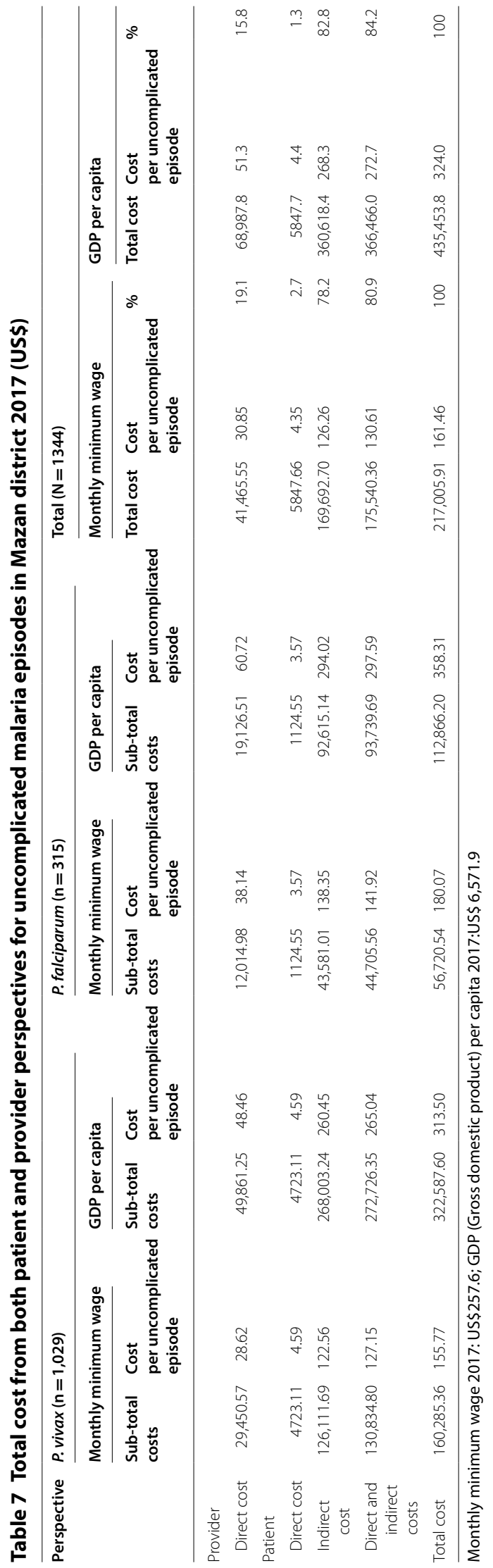




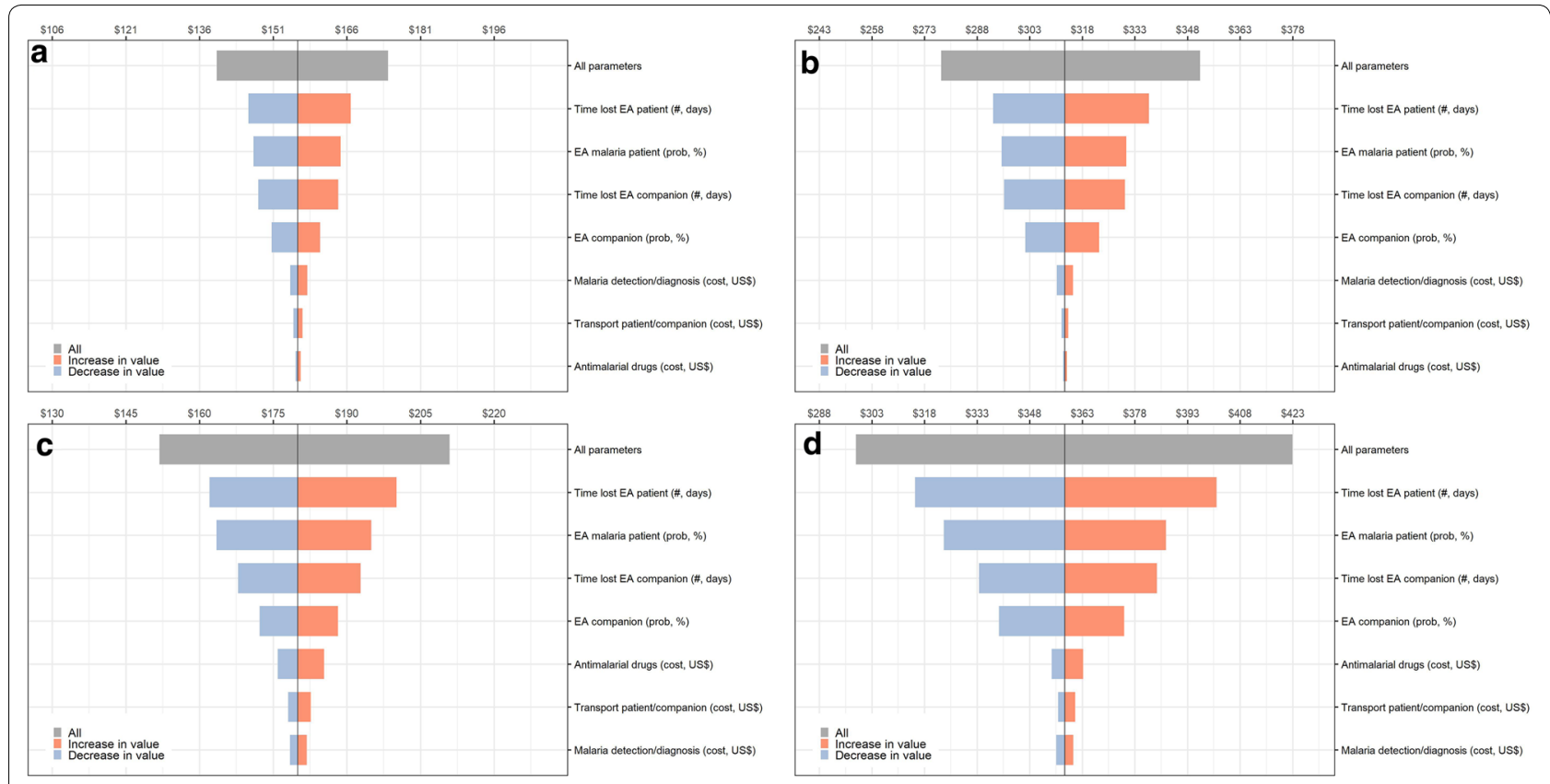

Fig. 2 Tornado diagram showing results of probabilistic sensitivity analysis (PSA) exploring the effect of key parameters on average costs per uncomplicated malaria episode in Mazan, 2017: a P. vivax episode, monthly minimum wage as reference to estimate person-day costs, b $P$. vivax episode, gross domestic product as reference to estimate person-day costs gross domestic product, $\mathbf{c}$. falciparum episode, monthly minimum wage as reference to estimate person-day costs, $\mathbf{d}$ P. falciparum episode, gross domestic product as reference to estimate person-day costs. One-way PSA (example: the lower the time lost in economically active (EA) patient, blue color, the lower the average costs per uncomplicated malaria episode); Multi-way PSA (gray color)

\section{Discussion}

This research provides total costs and average costs per episode associated with the detection and management of uncomplicated malaria in Mazan, an exemplar district in the Peruvian Amazon where poverty, limited accessibility from communities to health facilities, and healthcare-seeking behaviour challenge malaria control efforts. Estimated total costs for the 1344 uncomplicated malaria episodes registered in Mazan in 2017 were US\$ 217,006 with most of these costs (78\%) corresponding to indirect costs incurred by patients. Average costs per episode were higher for $P$. falciparum (US\$ 180) than for $P$. vivax (US\$156), mainly due to differences in costs of the anti-malarial treatment and in time losses due to illness. Indeed, the length of time lost due to illness in a patient, found to be associated with delayed confirmatory malaria diagnosis, was the parameter that caused most uncertainty in the average costs per malaria episode for both species.

As in Colombia [38], Brazil [39] and other endemic areas outside the Americas [19, 40, 41], uncomplicated malaria episodes in Mazan imposes significant costs on households, pushing poor families further into poverty. In several Amazonian communities with high risk of malaria transmission, the situation can become catastrophic due to the occurrence of repeated episodes in the same individuals and/or the same households every year [11, 38, 39, 42, 43]. In contrast to the low costs of transport and medications paid out of pocket by families, indirect costs of malaria episodes were the key determinant of the disease's overall costs. This is because adults have to interrupt their normal activities to care for ill family members, or the disease directly afflicts the economically active population [11, 40,44].

The indirect costs of a $P$. vivax episode is markedly higher in Mazan in 2017 (US\$ 260.45 with GDP; US\$ 122.56 with minimum wage) than in Afghanistan, Ethiopia, Indonesia and Vietnam in 2016 [45] and Papua New Guinea in 2013 [45]. This is partially due to Peru having a higher GDP per capita, which was used to estimate the lost wages of patients and their carers/companions. Specifically, in Papua, Indonesia, malaria associated costs may have been underestimated since they were calculated based on data collected in localities with high access to health facilities by road [40]. In the study area, the limited access to health facilities would also have increased the time lost due to illness with corresponding uncertainty for economically active patients and carers/companions during the period in which healthcare is sought for diagnosis, treatment and follow-up. As a result, the costs 
of case management of one $P$. vivax episode in Mazan (US\$ 313.50 based on GDP per capita, US\$ 155.77 based on minimum wages) were higher than the estimates in Papua, Indonesia (US\$ 44.50 based on mean wage) [40].

The association between longer time losses in a malaria patient and delayed malaria diagnosis could reflect a more compromised clinical case (without the need for hospitalization) that requires more recovery time. Indeed, several studies have shown an increase in malaria severity with a delay in malaria case management [20, $46,47]$, thus the WHO's recommendation of insuring access to early diagnosis, and prompt, effective treatment within 24-48 h of the onset of malaria symptoms [30]. The reduced group of participants (37.1\%) with malaria diagnosis within $48 \mathrm{~h}$ of onset of symptoms suggests that the delay in the malaria diagnosis remains a pitfall of the malaria case management in the rural and widely dispersed population of the Peruvian Amazon, as previously found by a longitudinal study (2001-2003) in riverine and road-associated rural populations of peri-Iquitos districts $[48,49]$.

It was not surprising to find that the availability of RDTs in the first place to which enrolled participants sought for healthcare (i.e. CHW or health posts) reduced the time from the onset of symptoms to malaria diagnosis. The impact of incorporating the use of RDTs to get timely diagnosis and appropriate treatment has already been demonstrated in rural Amazonian communities [48, 49]. Where RDTs were not available in the study communities, unreliable or irregular fluvial transport and limited access to the health centre in MT may have delayed any patient reference and/or sending of blood smear samples for malaria confirmation [50]. However the findings show that even with an easy access to malaria diagnosis, an early malaria case management of participants was not guaranteed [48]. The time to diagnosis of three or more days in several participants who went directly to health facility or CHW with RDTs available, suggest a delay in seeking care. The community's knowledge, misperceptions (e.g. perceiving malaria as a common, uneventful, and a mild and self-limiting disease), the lack of household involvement in community control of malaria, and initial self-treatment (e.g. use of antipyretics and refreshing herbs at home) reported in the KAP survey may be associated with such delay to seek care [51-53].

Several studies have highlighted the need for economic research on the household costs of illness, household responses, and their implications for poverty [44]. The lack of knowledge about the economic burden of illness for households and/or the poor understanding about the effects on the quality of life and well-being in the population may lead health stakeholders to plan and deliver health services with the main goals of increasing coverage and reducing disease burden. This decision-making process may be more obvious in the case of services that are provided free-of-charge like the detection, diagnosis and treatment of malaria provided by the Peruvian $\mathrm{MoH}$ in the entire country $[54,55]$. Increased access to prevention measures (e.g. delivery of long lasting insecticide treated bed nets) and malaria behaviour change communication (BCC) strategies would remain as the best options to avoid indirect and direct household costs due to malaria.

Similar to other studies conducted in Peru [11, 49], the provider in Mazan had to use more resources for delivering diagnosis and treatment services to an individual with a $P$. falciparum episode than one with a $P$. vivax episode. This was also observed in Papua, Indonesia, where the cost differences between both species were associated with additional consultations, transportation to the health facility and lost wages per episode [40]. The difference in costs of first-line treatment regimens between species (US\$ 8.76 for $P$. falciparum and US\$ 1.32 for $P$. vivax) explains well the higher provider costs of a $P$. falciparum episode. Delays in adjusting the daily dosage of one of the drugs (MQ) that make up the anti-malarial combined regimen for $P$. falciparum (MQ $+\mathrm{AS}+\mathrm{PQ}$ ) according to national policies have made difficult and expensive the procurement of separate presentations of these drugs because low volumes are less interesting for pharmaceutical companies, ceteris paribus. These delays have also prevented the purchase of cheaper drug presentations (AS-MQ fixed dose combinations instead of separate drug blisters) [56], which are used in other South-American countries such as Bolivia, Brazil and Venezuela $[57,58]$. The uncertainty in the unit cost of the anti-malarial treatment for $P$. falciparum likely depends on these procurement issues.

This study has a number of limitations. First, budget constraints did not allow to include all the $70 \mathrm{com}$ munities of Mazan and to visit households more than three times to maximize participation in the socioeconomic survey; however, the chosen communities (accounting for $80 \%$ of malaria incidence) and the cost parameters obtained from the survey likely reflect the case-management's situation in the district. Second, verbal report of time losses due to illness and costs may affect the accuracy of the cost estimates from the patient perspective. This possibility was reduced with a short recall. Third, productivity changes may occur because of absence from work (absenteeism) or because of reduced productivity while at work (presenteeism). This information may be derived from existing data sources, such as registrations from occupational health service companies. Nonetheless, such registrations are typically available only for salaried workers and not for self-employed 
workers, such as subsistence farmers [59]. Fourth, from a patient perspective, indirect costs for children were considered zero as they should not be economically active. However, children represent a risk group and as $41 \%$ of the population were children, the methods for valuing the productivity costs could lead to biased estimates; this could be due to educational losses. Fifth, malaria infection can cause macroeconomic costs, which cannot be assessed in this study at the household level. For example, malaria can affect foreign direct investments, international trade and tourism. Sixth, mental stress and social costs of families with sick members were not included, which are in general very difficult to evaluate over a short period of time (and are typically not monetised in health economic evaluations). Finally, as this study was focused on uncomplicated malaria, costs may have been underestimated due to the exclusion of the cost of primaquineinduced haemolysis and the cost of adverse effects. Primaquine-induced haemolysis was not included in any of the estimates due to uncertainty related to its frequency and severity. In countries that are prescribing primaquine without testing for glucose-6-phosphate dehydrogenase (G6PD) deficiency, as in Peru, it is possible that haemolysis already occurs, however in previous studies, Peru has reported low $(<2 \%)$ G6PD deficiency [60].

\section{Conclusions}

Access to prompt diagnosis and treatment is one of the principal strategies for malaria control and elimination. This includes two components, one dependent upon the patient to seek care when sick and the other being the availability of accessible diagnosis and treatment facilities. Although malaria case management is provided free-of-charge by the $\mathrm{MoH}$ in Peru, this study confirmed that malaria poses a significant economic burden on rural households and individuals in terms of indirect costs due to the loss of working days. These costs are not well perceived by society and the substantial financial impact of the disease may be undervalued in public policy planning. Malaria control policies need to be integrated into development and poverty reduction programmes as socioeconomic development may be an effective and sustainable intervention against malaria in the long term.

\section{Supplementary information}

Supplementary information accompanies this paper at https://doi. org/10.1186/s12936-020-03233-5.

Additional file 1: Table S1. Knowledge of household heads on malaria. Table S2. Attitudes of household heads on malaria. Table S3. Malaria prevention practices among household heads. Table S4. Malaria episodes and household by basin. Table S5. Direct cost from the provider perspective for uncomplicated malaria by P. vivax in Mazan district 2017 (US\$). Table S6. Direct cost from the provider perspective for uncomplicated malaria by P. falciparum in Mazan district 2017 (US\$). Table S7. Direct and indirect costs from the patient perspective for uncomplicated malaria by P. vivax in Mazan district 2017 (US\$). Table S8. Direct and indirect costs from the patient perspective for uncomplicated malaria by $P$. falciparum in Mazan district 2017 (US\$).

\section{Abbreviations}

ACD: Active case detection; API: Annual parasite index; AS: Artesunate; BCC: Behaviour change communication; $\mathrm{BH}$ : Bello Horizonte; $\mathrm{Cl}$ : Confidence interval; CJ: Catorce de Julio; CHW: Community health workers; CQ: Chloroquine; EsSalud: Social health insurance system; FFAA: Armed Forces; GDP: Gross Domestic Product; G6PD: Glucose-6-phosphate dehydrogenase; GNI: Gross national income; HRP-II: Histidine-rich protein II; HU: Huaman-Urco; IHIS: Integrated Health Insurance Scheme; KAP: Knowledge, attitudes and practices; LI: Libertad; LM: Light microscopy; MA: Mangua; MQ: Mefloquine; MT: Mazan town; MoH: Ministry of Health; MDGs: Millennium Development Goals; NMCP: National Malaria Control Program; ODK: Open Data Kit; PCD: Passive case detection; PLDH: Plasmodium lactate dehydrogenase; PQ: Primaquine; PAB: Puerto Abeja; PA: Puerto Alegre; PE: Primero de Enero; PEN: Peruvian Nuevos Soles; PO: Puerto Obrero; PU: Puinahua; PNP: National Police; RDT: Rapid diagnostic test; SA: Salvador; SZ: San Antonio de Zambrano; SC: Santa Cruz; SF: San Francisco de Buen Paso; SU: Sucusari; SDGs: Sustainable Development Goals; TA: Tamanco; US\$: United States Dollars; UM: Urco Miraño; VB: Visto Bueno; WHO: World Health Organization.

\section{Acknowledgements}

We would like to thank inhabitants of selected communities in Mazan.

\section{Authors' contributions}

Conceptualization, AL-C, DG, HR, NS, AR-A and PB; Data curation, DM-G, JLB, KA and AR-A; Formal analysis, DM-G and AR-A; Funding acquisition, AL-C, PB, NS and ARA; Investigation, JLB, JC-M, DG, KA; Methodology, DM-G, PB, JB, NS and AR-A; Project administration, AL-C and AR-A; Resources, RB and M-PH; Software, DM-G, NS and AR-A; Supervision, AL-C, NS and AR-A; Validation, DM-G, AL-C, NS and AR-A; Visualization, DM-G and AR-A; Writing-original draft, DM-G and AR-A; Writing - review \& editing, DM-G, AR-A, AL-C, JB, JLB, $M-P H, J C-M, K A, D G, H R$, NS and PB; All authors read and approved the final manuscript.

\section{Funding}

This study was funded by the Peruvian National Council of Science - Concytec (008-2014-FONDECYT) and the Académie de Recherche et d'Enseignement Supérieur-Commission de la Coopération au Développement of Belgium (ARES-CCD, PRD-Peru 2014-2019).

Availability of data and materials

All data generated during this study are included in this published article and its Additional file 1.

\section{Ethical approval and consent to participate}

Ethics clearance for the study was obtained from the Ethics Review Board of the Universidad Peruana Cayetano Heredia, Lima, Peru (SIDISI code \# 64371). Permissions were received from health and local authorities after explaining the purpose and procedures of the study. Signed informed consent was obtained prior the study enrollment to participation and blood sampling by all adults and the parents of all participating children $<18$ years. In addition to parental/guardian consent, children older than 7 years provided a signed informed assent. All the methods were carried out in accordance with approved guidelines.

\section{Consent for publication}

Written consents were obtained from patients.

\section{Competing interests}

The authors declare no conflict of interest. 


\begin{abstract}
Author details
1 Facultad de Medicina Humana, Universidad Nacional de la Amazonía Peruana, Iquitos, Loreto 160, Peru. ${ }^{2}$ Research Institute of Health and Society (IRSS), Université Catholique de Louvain, 1200 Brussels, Belgium. ${ }^{3}$ Centre for Health Economics Research and Modelling Infectious Diseases, Vaccine and Infectious Disease Institute, University of Antwerp, 2000 Antwerp, Belgium. ${ }^{4}$ Fund for Scientific Research FNRS, 1000 Brussels, Belgium. ${ }^{5}$ Instituto de Medicina Tropical "Alexander von Humboldt", Universidad Peruana Cayetano Heredia, Lima 31, Peru. ${ }^{6}$ Facultad de Salud Pública y Administración, Universidad Peruana Cayetano Heredia, Lima 31, Peru. ${ }^{7}$ Department of Clinical Microbiology, Center for Interdisciplinary Research on Medicines (CIRM), University Hospital of Liège, 4000 Liège, Belgium. ${ }^{8}$ Laboratorios de Investigación y Desarrollo, Facultad de Ciencias y Filosofia, Universidad Peruana Cayetano Heredia, Lima 31, Peru. ${ }^{9}$ Departamento de Ciencias Celulares y Moleculares, Facultad de Ciencias y Filosofia, Universidad Peruana Cayetano Heredia, Lima 31, Peru.
\end{abstract}

Received: 28 November 2019 Accepted: 10 April 2020 Published online: 21 April 2020

\section{References}

1. Huicho L, Segura ER, Huayanay-Espinoza CA, de Guzman JN, RestrepoMéndez MC, Tam Y, et al. Child health and nutrition in Peru within an antipoverty political agenda: a countdown to 2015 country case study. Lancet Glob Health. 2016;4:e414-26.

2. United Nations. Transforming our world: the 2030 agenda for sustainable development. In: Rosa W, editors. A new era in global health. New York: Springer Publishing Company; 2017. https://connect.springerpub.com/ lookup/doi/10.1891/9780826190123.ap02. Accessed 12 May 2019.

3. The World Bank. https://data.worldbank.org/indicator/SH.XPD.CHEX. GD.ZS?end $=2016 \&$ locations $=$ PE\&start $=2000$.

4. Petrera $M$, Valdivia $M$, Jimenez $E$, Almeida G. Equity in health and health care in Peru, 2004-2008. Rev Panam Salud Pública. 2013;33:131-6.

5. Ministerio de Salud. Dirección General de Epidemiología. Boletín Epidemiológico No 52. Lima: Peru; 2012. http://www.dge.gob.pe/bolet ines/2012/52.pdf. Accessed 1 Jun 2019.

6. Solano-Villarreal E, Valdivia W, Pearcy M, Linard C, Pasapera-Gonzales J, Moreno-Gutierrez D, et al. Malaria risk assessment and mapping using satellite imagery and boosted regression trees in the Peruvian Amazon. Sci Rep. 2019;9:15173.

7. Rosas-Aguirre A, Gamboa D, Manrique P, Conn JE, Moreno M, Lescano AG, et al. Epidemiology of Plasmodium vivax malaria in Peru. Am J Trop Med Hyg. 2016;95:133-44.

8. WHO. World malaria report 2018. Geneva: World Health Organization; 2018. http://www.who.int/malaria/publications/world-malaria-repor t-2018/report/en/. Accessed 18 Jan 2019.

9. Ministerio de Salud-Centro Nacional de Epidemiología, Prevención y Control de Enfermedades. Sala situacional de Salud. Report No. 52. Lima: Peru; 2017. https://www.dge.gob.pe/portal/index.php?option=com_ content\&view $=$ article\&id=606Accessed 1 Jun 2019

10. Chuquiyauri R, Paredes M, Peñataro P, Torres S, Marin S, Tenorio A, et al. Socio-demographics and the development of malaria elimination strategies in the low transmission setting. Acta Trop. 2012;121:292-302.

11. Ministerio de Salud. Proyecto Vigia. Impacto económico de la malaria en el Perú. Lima: Peru; 1999, p. 127. http://bvs.minsa.gob.pe/local/minsa 11763.pdf. Accessed 10 Jun 2019.

12. WHO. Global Health Workforce Alliance: Peru. Geneva, World Health Organization. https://www.who.int/workforcealliance/countries/per/en/. Accessed 22 Apr 2019.

13. Plan Esencial de Aseguramiento en Salud (PEAS). http://www.sis.gob.pe/ asegurados/listado-de-cobertura.asp. Accessed 23 Apr 232019.

14. WHO. Primary health care systems (PRIMASYS): Case study from Peru, abridged version. Geneva: World Health Organization, 2017. https:// www.who.int/alliance-hpsr/projects/alliancehpsr_peruabridgedprimasys .pdf?ua=1. Accessed 22 Apr 2019.

15. Seguro Integral de Salud_SIS. http://www.sis.gob.pe/asegurados/tipos -de-seguro/sis-gratuito.asp. Accessed 30 Apr 2019.

16. Instituto Nacional de Estadística e Informática. Mujeres y hombres con Seguro Integral de Salud (SIS), según ámbito geográfico. https:// www.inei.gob.pe/buscador/?tbusqueda=seguro+integral+de+salud. Accessed 23 Apr 2019.

17. WHO. Disease surveillance for malaria elimination: operational manual. Geneva: World Health Organization, 2012. https://www.who.int/malaria/ publications/atoz/9789241503334/en/. Accessed 30 Apr 2019.

18. Moreno-Gutierrez D, Llanos-Cuentas A, Luis Barboza J, Contreras-Mancilla J, Gamboa D, Rodriguez H, et al. Effectiveness of a malaria surveillance strategy based on active case detection during high transmission season in the Peruvian Amazon. Int J Environ Res Public Health. 2018;15:e2670.

19. Devine A, Kenangalem E, Burdam FH, Anstey NM, Poespoprodjo JR, Price RN, et al. Treatment-seeking behavior after the implementation of a unified policy of dihydroartemisinin-piperaquine for the treatment of uncomplicated malaria in Papua, Indonesia. Am J Trop Med Hyg. 2018;98:543-50.

20. Ministerio de Salud. Factores de Riesgo de la Malaria Grave en el Perú. Lim: Peru; 2001. http://bvs.minsa.gob.pe/local/minsa/1772.pdf. Accessed 29 Apr 2019.

21. Parker BS, Paredes Olortegui M, Peñataro Yori P, Escobedo K, Florin D, Rengifo Pinedo S, et al. Hyperendemic malaria transmission in areas of occupation-related travel in the Peruvian Amazon. Malar J. 2013;12:178.

22. Establecimientos de Salud Loreto. ftp.minsa.gob.pe/sismed/establecim ientos/disasdiresas/EESS\%20-\%20LORETO.xIs. Accessed 11 Apr 2019.

23. WHO. Malaria Microscopy. Quality Assurance Manual. 2nd ed. Geneva: World Health Organization; 2016. https://www.who.int/malaria/publi cations/atoz/9789241549394/en/. Accessed 12 Apr 2019.

24. WHO. Prequalification of In Vitro Diagnostics. Geneva: World Health Organization. https://www.who.int/diagnostics_laboratory/evaluations/ pq-list/malaria/190129_amended_pqpr_0297_012_00_v2.pdf. Accessed 11 Apr 2019.

25. Ministerio de Salud. Norma técnica para la atención de la malaria y malaria severa en el Perú. Iquitos: Peru; 2015. http://bvs.minsa.gob.pe/ local/MINSA/4373.pdf. Accessed 13 Apr 2019.

26. Llanos-Cuentas A, Lacerda MV, Rueangweerayut R, Krudsood S, Gupta SK, Kochar SK, et al. Tafenoquine plus chloroquine for the treatment and relapse prevention of Plasmodium vivax malaria (DETECTIVE): a multicentre, double-blind, randomised, phase $2 \mathrm{~b}$ dose-selection study. Lancet. 2014;383:1049-58.

27. Marquino W, Huilca M, Calampa C, Falconi E, Cabezas C, Naupay R, et al. Efficacy of mefloquine and a mefloquine-artesunate combination therapy for the treatment of uncomplicated Plasmodium falciparum malaria in the Amazon Basin of Peru. Am J Trop Med Hyg. 2003;68:608-12.

28. Heggenhougen HK, Hackethal V, Vivek P. The behavioural and socia aspects of malaria and its control. An introduction and annotated bibliography. Geneva: World Health Organization, 2003. https://apps.who.int/ iris/handle/10665/42504. Accessed 13 Apr 2019.

29. Instituto Nacional de Estadística e Informática. Directorio de Comunidades Nativas y Campesinas. Censos Nacionales 2017, vol I. Lima: Peru; 2018. https://www.inei.gob.pe/media/MenuRecursivo/publicacio nes_digitales/Est/Lib1597/TOMO_01.pdf. Accessed 13 Apr 2019.

30. WHO. Guidelines for the treatment of malaria. 3rd ed. Geneva: World Health Organization; 2015, p. 316. https://www.who.int/malaria/publi cations/atoz/9789241549127/en/. Accessed 12 Apr 2019.

31. Ministerio de Salud. Documento Técnico "Metodología para la Estimación de Costos Estándar en los Establecimientos de Salud". Resolución Ministerial No 195-2009-MINSA. Lima: Peru; 2009. http://gestionensalud. medicina.unmsm.edu.pe/wp-content/uploads/2015/10/EVALUA_RB_05_ DGSP 2006 Metodologia Costeo.pdf.

32. Richardson SC, Hussmanns R, Mehran F, Verma V. Surveys of economically active population, employment, unemployment and underemployment. Statistician. 1992;41:249.

33. Instituto Nacional de Estadística e Informática. Indicadores de Empleo e Ingreso por departamento Perú 2007-2017. Lima: Peru; 2018. https:// www.inei.gob.pe/media/MenuRecursivo/publicaciones_digitales/Est/ Lib1537/libro.pdf. Accessed 12 Apr 2019.

34. Decreto Legislativo No 854. Ley de Jornada de Trabajo, Horario y Trabajo en Sobretiempo. http://www.leyes.congreso.gob.pe/Documentos/Decre tosLegislativos/00854.pdf. Accessed 12 Apr 2019.

35. Briggs A, Sculpher M, Claxton K. Decision Modelling for health economic evaluation. Oxford: New York; 2006. https://global.oup.com/academic/ product/decision-modelling-for-health-economic-evaluation-97801 $98526629 ? c c=$ be\&lang $=e n \&$. Accessed 13 Apr 2019. 
36. Gray A, Clarke P, Wolstenholme J, Wordsworth S. Applied Methods of Cost-effectiveness Analysis in Healthcare. Oxford: New York; 2011. https:// global.oup.com/academic/product/applied-methods-of-cost-effectiven ess-analysis-in-healthcare-9780199227280?cc=be\&lang=en\&. Accessed 13 Apr 2019.

37. GDP per capita (current US\$). Data. https://data.worldbank.org/indicator/ ny.gdp.pcap.cd?locations=pe. Accessed 12 Apr 122019.

38. Sicuri E, Bardají A, Sanz S, Alonso S, Fernandes S, Hanson K, et al. Patients' costs, socio-economic and health system aspects associated with malaria in pregnancy in an endemic area of Colombia. PLoS Negl Trop Dis. 2018;12:e0006431.

39. Bôtto-Menezes C, Bardají A, Dos Santos Campos G, Fernandes S, Hanson $\mathrm{K}$, Martínez-Espinosa FE, et al. Costs associated with malaria in pregnancy in the Brazilian Amazon, a low endemic area where Plasmodium vivax predominates. PLoS Negl Trop Dis. 2016;10:e0004494.

40. Karyana M, Devine A, Kenangalem E, Burdarm L, Poespoprodjo JR, Vemuri $R$, et al. Treatment-seeking behaviour and associated costs for malaria in Papua, Indonesia. Malar J. 2016;15:536.

41. Morel CM, Thang ND, Xa NX, Hung LX, Thuan LK, Van Ky P, et al. The economic burden of malaria on the household in south-central Vietnam. Malar J. 2008;7:166.

42. Van den Eede P, Soto-Calle VE, Delgado C, Gamboa D, Grande T, Rodriguez $\mathrm{H}$, et al. Plasmodium vivax sub-patent infections after radical treatment are common in Peruvian patients: results of a 1-year prospective cohort study. PLoS ONE. 2011;6:e16257.

43. Chuquiyauri R, Peñataro P, Brouwer KC, Fasabi M, Calderon M, Torres S, et al. Microgeographical differences of Plasmodium vivax relapse and reinfection in the Peruvian Amazon. Am J Trop Med Hyg. 2013;89:326-38.

44. Russell $\mathrm{S}$. The economic burden of illness for households in developing countries: a review of studies focusing on malaria, tuberculosis, and human immunodeficiency virus/acquired immunodeficiency syndrome. Am JTrop Med Hyg. 2004;71(Suppl 2):147-55.

45. Devine A. The economics of vivax malaria treatment. 2018 Aug 22. https ://thesiscommons.org/zsc6x/. Accessed 16 Nov 2019.

46. Llanos-Chea F, Martínez D, Rosas A, Samalvides F, Vinetz JM, LlanosCuentas A. Characteristics of travel-related severe Plasmodium vivax and Plasmodium falciparum malaria in individuals hospitalized at a tertiary referral center in Lima, Peru. Am J Trop Med Hyg. 2015;93:1249-53.

47. Lima ISF, Duarte EC. Factors associated with timely treatment of malaria in the Brazilian Amazon: a 10-year population-based study. Pan Am J Public Health. 2017;41:e100.

48. Casapía M, Vásquez LE, Rosas Á, Pinedo-Ríos N, Cabezas C, Chang J. Mejora en el diagnóstico y tratamiento oportuno de malaria con el uso de pruebas rápidas por promotores de salud en la Amazonía Peruana. Rev Peru Med Exp Salud Publica. 2008;361-8.

49. Aguirre RAM, Zavalaga LLF, Belaunde TM. Cost-effectiveness ratio of using rapid tests for malaria diagnosis in the Peruvian Amazon. Rev Panam Salud Publica. 2009;25:377-88 (in Spanish).
50. Durand VS, Ramal AC, Huilca M, Cabezas SC. Oportunidad en el diagnóstico y tratamiento de la malaria en comunidades periurbanas de la amazonía peruana. Rev Peru Med Exp Salud Publica. 2005;22:47-53.

51. Giao PT, Vries PJ, Binh TQ, Nam NV, Kager PA. Early diagnosis and treatment of uncomplicated malaria and patterns of health seeking in Vietnam. Trop Med Int Health. 2005;10:919-25.

52. Grietens KP, Soto V, Erhart A, Ribera JM, Toomer E, Tenorio A, et al. Adherence to 7-day primaquine treatment for the radical cure of $P$. vivax in the Peruvian Amazon. Am J Trop Med Hyg. 2010;82:1017-23.

53. Adhikari B, Phommasone K, Pongvongsa T, Koummarasy P, Soundala $X$, Henriques $G$, et al. Treatment-seeking behaviour for febrile illnesses and its implications for malaria control and elimination in Savannakhet Province, Lao PDR (Laos): a mixed method study. BMC Health Serv Res. 2019;19:252.

54. Pigott DM, Atun R, Moyes $\mathrm{CL}$, Hay SI, Gething PW. Funding for malaria control 2006-2010: a comprehensive global assessment. Malar J. 2012;11:246.

55. Durand S, Lachira-Alban A, Sánchez CC. Impact on the transmission of malaria with different treatment schemes in the peruvian coast and amazon region within the framework of a policy on antimalarial medications, 1994-2017. Rev Peru Med Exp Salud Publica. 2018;35:497-504 (in Spanish).

56. The Global Fund. Price \& quality reporting price reference Report. https:// public.tableau.com/profile/the.global.fund\#!/vizhome/PQRPricelist_Engli sh/PriceList. Accessed 15 Oct 2019.

57. Recht J, Siqueira AM, Monteiro WM, Herrera SM, Herrera S, Lacerda MVG. Malaria in Brazil, Colombia, Peru and Venezuela: current challenges in malaria control and elimination. Malar J. 2017;16:273.

58. SIAPS. Informe técnico: Evaluación de la situación de la gestión del suministro de medicamentos antimaláricos en los países miembros de la Iniciativa para el Control de la Malaria en la Cuenca del Amazonas. Presentado a la Agencia de los Estados Unidos para el Desarrollo Internacional por el Programa Systems for Improved Access to Pharmaceuticals and Services (SIAPS). Arlington: Management Sciences for Health. 2015. https://apps.who.int/medicinedocs/es/m/abstract/Js21876es/. Accessed 10 May 2019

59. Bouwmans CKM, Severens HKM, Brouwer WHRL. The iMTA productivity cost questionnaire: a standardized instrument for measuring and valuing health-related productivity losses. Value Health. 2015;8:753-8.

60. Monteiro WM, Val FF, Siqueira AM, Franca GP, Sampaio VS, Melo GC, et al. G6PD deficiency in Latin America: systematic review on prevalence and variants. Mem Inst Oswaldo Cruz. 2014;109:553-68.

\section{Publisher's Note}

Springer Nature remains neutral with regard to jurisdictional claims in published maps and institutional affiliations.

Ready to submit your research? Choose BMC and benefit from

- fast, convenient online submission

- thorough peer review by experienced researchers in your field

- rapid publication on acceptance

- support for research data, including large and complex data types

- gold Open Access which fosters wider collaboration and increased citations

- maximum visibility for your research: over $100 \mathrm{M}$ website views per year

At BMC, research is always in progress.

Learn more biomedcentral.com/submissions 